\title{
The potential of the male anal Pap smear
}

\author{
M. B. O'Connor
}

Received: 22 September 2009/Accepted: 9 October 2009/Published online: 17 November 2009

(C) Royal Academy of Medicine in Ireland 2009

\section{Dear Editor,}

We read with great interest the publication by Oon et al. [1] on the topic of Pap smears for men. As correctly reported by Oon et al., anal intraepithelial neoplasia (AIN) which can lead to anal carcinoma is the equivalent to the highly publicised cervical intraepithelial neoplasia (CIN) and cervical carcinoma. With anal carcinoma incidence continuing to rise in both men and woman by 96 and 39\%, respectively, over the last three decades this forgotten anal pathology is as important as its cervical counterpart.

In a presentation at the 20th Annual Australasian Society for HIV Medicine conference, Hillman et al. [2] presented data on the cost effectiveness of screening for anal cancer among HIV positive men who have sex with men (MSM). The basis for this research is the fact that anal squamous cell carcinoma occurs at the rate of approximately 30-92 cases per 100,000 in HIV positive MSM, along with the fact that despite surgery, chemotherapy and radiotherapy, in 2004, overall 5-year survival in Australia was $64 \%$. This compared to 2002 rates of cervical cancer among the general Australian female population being 6.9 cases per 100,000 and a 5-year survival of 74\%.

The data presented by Hillman were based on the fact that there are a total of 12,700 HIV positive MSM in Australia. From this, it was estimated that 7.5 (range 3.6-11.7) cases of anal carcinoma will develop per year in these men. With anal pap smears reported as being $81 \%$ sensitive, this would result in 6 cases being detected among this cohort or 2,116 HIV positive MSM would need to be

M. B. O’Connor ( $\square)$

Department of Medicine, South Infirmary,

Victoria University Hospital, Cork, Ireland

e-mail: mortimeroconnor@gmail.com screened per case diagnosed. In comparison, the New South Wales Pap Register recorded 681,306 cervical Pap smears in 2005, when the incident cervical carcinoma rate of 238 cases per year, giving a diagnosis rate of 1 case per 2,862 cervical Pap smears.

From a costing perspective, a USA paper in 1999 estimated the cost per QALY for anal carcinoma screening in HIV positive MSM every 2 years was $\$ 13,000$ [3]. In comparison, the most recent Australian figures indicate that the cost per QALY for cervical screening is significantly higher at $\$ 21,707$.

From the publication by Oon et al. and the work of Hillman et al., it would suggest that an intervention targeting HIV positive MSM with anal Pap smears to screen for anal carcinoma would be of comparable value and costs to that of the existing cervical carcinoma screening program. In addition to the potential benefits of anal screening in this population, the potential use of the HPV vaccination in this population must also be considered [4].

\section{References}

1. Oon SF, Hanly A, Winter DC (2009) Pap smears for men: a vision of the future? Ir J Med Sci (Epub ahead of print)

2. Hillman R, Botes L (2008) Cost effectiveness of screening for anal cancer in HIV positive MSM Oral Presentation. In: 20th annual Australasian Society for HIV Medicine conference, Perth, Australia, 17th September 2008

3. Goldie SJ, Kuntz KM, Weinstein MC, Freedberg KA, Welton ML, Palefsky JM (1999) The clinical effectiveness and cost-effectiveness of screening for anal squamous intraepithelial lesions in homosexual and bisexual HIV-positive men. JAMA 281(19):18221829

4. O'Connor MB, O'Connor C (2009) The HPV vaccine for men. Int J STD AIDS 20(4):290-291 